\title{
İdiyopatik Osteosklerozis Sıklığı ve Dağılımının Belirlenmesi
}

\author{
Determination of Idiopathic Osteosclerosis Frequency and Distribution
}

\author{
Melek TAŞSÖKER $^{* 1}$ (D) \\ dishekmelek@gmail.com
}

\author{
Duygu AZMAN ${ }^{1}$ iD \\ duygudenti@hotmail.com
}

\section{ÖZ}

Amaç: Bu çalışmanın amacı çene kemiklerinde görülen idiyopatik osteosklerozis (IO)'nun sıklığını, yaş, cinsiyet ve çenede yerleşim bölgesine göre dağılımını panoramik radyografiler aracılığı ile belirlemektir.

Gereç ve Yöntemler: Çalıșmada 16-92 yaș aralığında 1150 hastanın (613 kadın, 537 erkek) panoramik radyografisi retrospektif olarak incelenmiştir. Çevresinde radyolüsensi bulunmayan, normal kemikle ilişkili, sınırları düzenli, semptom göstermeyen, 3 mm'den büyük uniform radyoopasiteler IO olarak değerlendirilmiștir. IO bulunan çene bölgesi (sağ-sol; mandibula/maksilla; anterior-premolar-molar), IO'nun komșu dișlerle ilișkisi (apikal-interradiküler-dișten bağımsız) ve IO'nun şekli (yuvarlak-eliptik-düzensiz) kayıt altına alınmıştır. Tanımlayıcı istatistikler hesaplanmış ve kategorik verilerin analizinde ki-kare testi uygulanmıştır. Test sonuçlarının anlamlılıkları $\mathrm{p}<0.05$ seviyesine göre değerlendirilmiștir.

Bulgular: 1150 hastanın 103'ünde (\%9) toplam 122 IO lezyonu saptandı. Lezyonların tamamı mandibulada görüldü. Lezyonların görülme sıklığı ile yaş ve cinsiyet arasında anlamlı farklılık saptanmadı ( $\mathrm{p}>0.05$ ). IO en sık mandibula molar bölgede (\%45.9) daha sonra premolar bölgede (\%25.4) çoğunlukla düzensiz șekilli olarak (\%78.7) izlendi. Lezyonların \%45.1 sağda, \%50'si sol mandibulada, \%4.9'u orta hat bölgesinde ve en sık dișten bağımsız mandibular alveolar kemikte (\%70.5) yerleșim göstermekteydi.

Sonuç: İncelenen populasyonda IO, yaş ve cinsiyet parametrelerinden bağımsız gözlemlenen \%9 sıklığa sahip bir lezyondur.

Anahtar Kelimeler: İdiyopatik osteosklerozis, Yoğun kemik adası, Panoramik radyograf

Geliș: 18.02 .2021

Kabul: 22.03 .2021

Yayın: 30.04.2021

\begin{abstract}
Aim: The aim of this study is to determine the frequency of idiopathic osteosclerosis (IO) seen in the jaws, its distribution according to age, gender and jaw settlement area by means of panoramic radiographs.

Material and Methods: In the study, panoramic radiography of 1150 patients ( 613 women, 537 men) between the ages of 16-92 were retrospectively analyzed. Uniform radiopacities larger than $3 \mathrm{~mm}$, with no surrounding radiolucency, associated with normal bone, with regular borders, without symptoms, were evaluated as IO. The jaw region with IO (right-left; mandible/maxilla; anterior-premolar-molar), relation of IO with neighboring teeth (apical-interradicular-independent from tooth region) and shape of IO (round-elliptic-irregular) were recorded. Descriptive statistics were calculated and the chi-square test was used in the analysis of categorical data. The significance of the test results was evaluated according to the $p<0.05$ level.

Results: A total of 122 IO lesions were detected in 103 (9\%) of 1150 patients. All lesions were seen in the mandible. There was no significant difference between the incidence of lesions and age and gender ( $>0.05)$. IO was most frequently observed in the molar region of the mandible (45.9\%) and then in the premolar region (25.4\%) with an irregular shape (78.7\%). $45.1 \%$ of the lesions were located in the right mandible, $50 \%$ in the left mandible, $4.9 \%$ in the midline region and the most common tooth-independent mandibular alveolar bone (70.5\%).

Conclusion: In the studied population, IO is a lesion with a frequency of $9 \%$ observed independent of age and gender parameters.
\end{abstract}

Keywords: Idiopathic osteosclerosis, Dense bone island, Panoramic radiography

Received: 18.02 .2021

Accepted: 22.03 .2021

Published: 30.04 .2021

Atıf / Citation: Taşsöker M, Azman D. İdiyopatik osteosklerozis sıklığı ve dağılımının belirlenmesi. NEU Dent J. 2021;1:1-6.

* Sorumlu Yazar / Corresponding Author

1. Necmettin Erbakan Üniversitesi Diş Hekimliği Fakültesi Ağız, Diş ve Çene Radyolojisi AD Konya,

Türkiye
"This article is licensed under a Creative Commons AttributionNonCommercial 4.0 International License(CC BY-NC 4.0) 


\section{GíRIS}

Çenelerde görülen idiyopatik osteosklerozis (IO), nedeni bilinmeyen lokalize non-ekspansif radyoopasitelerdir. ${ }^{1}$ Çeneler dışında pelvis, femur ve diğer uzun kemiklerde de görülebilmektedirler. ${ }^{2}$ Bilinen diğer isimleri kemik skarı, yoğun kemik adası, enostozis ve fokal periapikal osteopetrozistir. ${ }^{3}$ Asemptomatik olduklarından farklı nedenlerle alınan radyografilerde tesadüfen teşhis edilirler. ${ }^{4}$ Kansellöz kemik içinde gelișen bu lezyon tedavi gerektirmez, klinik takip yeterlidir ${ }^{5}$ ancak enflamatuvar kaynaklı ya da sistemik hastalık nedeni ile gelişen ve tedavi gerektiren radyoopasitelerden ayırt edilmeleri gereklidir. ${ }^{3}$

Genellikle mandibulada ve premolar-molar bölgede görülürler. İnternal yapıları homojen olup, düzgün dış sınır yapısına sahip ve radyolüsent marjin göstermeyen kapsülsüz lezyonlardır. ${ }^{3}$ Nadiren diș kökü ile ilișkili oldukları durumlarda eksternal kök rezorbsiyonuna yol açabilmektedirler ancak bu kendini sınırlayan niteliktedir ve ilgili diş vitaldir. ${ }^{4}$ Büyüklükleri 2-3 mm'den 1-2 cm'ye kadar değiş̧ebilir. Dişlerin köklerinde, köklerin aralarında ya da dişlerden bağımsız çene arkı üzerinde herhangi bir alanda görülebilirler. ${ }^{6}$ Histolojik olarak medullar boşluk barındırmayan matür vital kemikten olușmakta ve enflamatuvar infiltrat bulundurmamaktadır. ${ }^{7}$ Tanısının radyolojik olarak konulması gereksiz biyopsi prosedürünü önlemektedir. ${ }^{7}$
Literatürde panoramik, periapikal radyografiler ve konik ıșınlı bilgisayarlı tomografi ile yürütülen çalışmalarda $\% 0.10^{7}$ - $\% 31^{8}$ sıklığında IO görüldüğü bildirilmiștir. Panoramik radyografiler çenelerde geniş bölgeleri incelemek açısından faydalı görünmektedir. ${ }^{6}$ Türk populasyonunda konuya ilişkin yürütülen çalıșma sayısı sınırlıdır. Bu çalıșmanın amacı çene kemiklerinde görülen IO'nun sıklığını, yaş, cinsiyet ve çenede yerleşim bölgesine göre dağılımını panoramik radyografiler üzerinden retrospektif olarak belirlemektir.

\section{GEREÇ VE YÖNTEMLER}

\section{Örneklem ve Çalışma dizaynı}

Çalışmamızda 2020-2021 yıllarında Ağız, Diş ve Çene Radyolojisi kliniğine tanı ve tedavi gereksinimi ile başvuran ve bu amaçlarla panoramik radyografisi çekilmiş olan 16-92 yaş aralığında 1150 hastanın kayıtları retrospektif olarak incelenmiştir. Çalışmamızın etik ilkelere uygunluğu Necmettin Erbakan Üniversitesi Diș Hekimliği Fakültesi İlaç ve Tibbi Cihaz Dışı Araştırmalar Etik Kurulu tarafından onaylanmıştır (Karar No: 2021/01-07).

Hastaların yaşı, cinsiyeti, IO varlığı, IO bulunan çene bölgesi (sağ-sol; mandibula/maksilla; anterior-premolar-molar), IO'nun komşu dişlerle ilişkisi (apikal-interradiküler-dişten bağımsız), IO'nun şekli (yuvarlak-eliptik-düzensiz) kayıt altına alınmıștır (Resim 1-3).

Resim 1: Sol alt kanin apikalinde düzensiz şekilli IO lezyonu

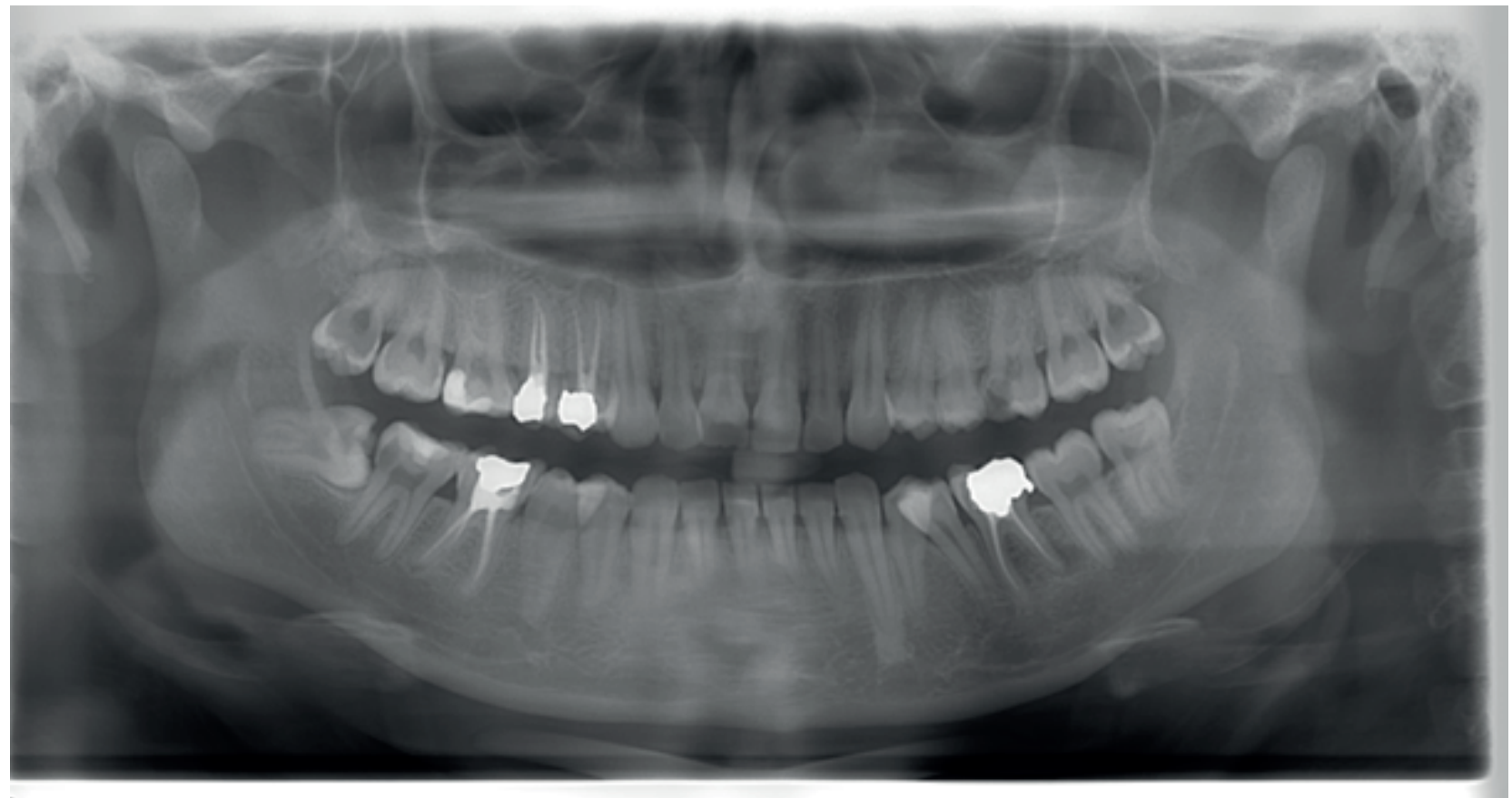


Resim 2: Sol alt premolar-molar bölgesinde diș köklerinden bağımsız yerleșim gösteren yuvarlak șekilli IO lezyonu

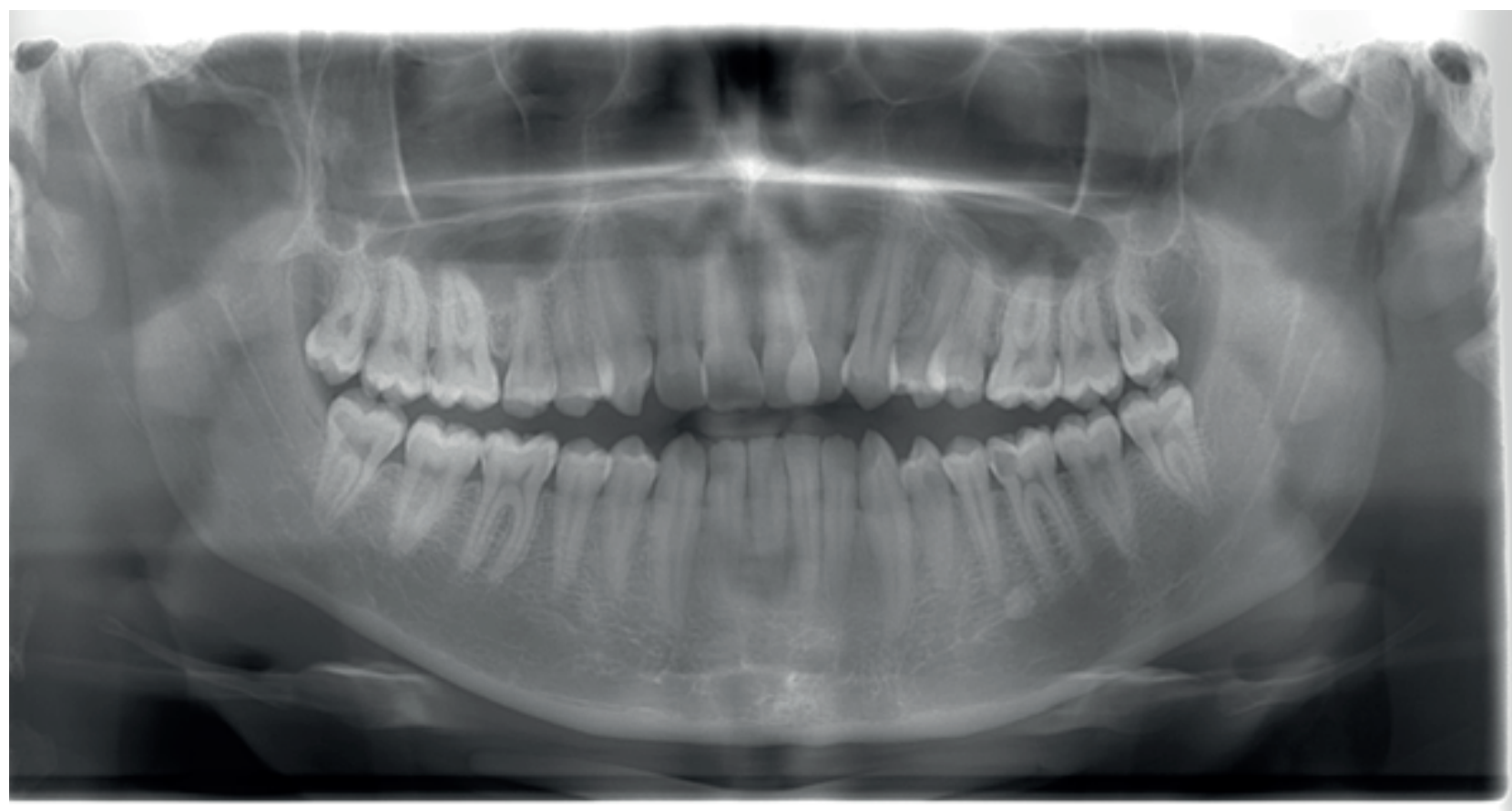

Resim 3: Sağ alt premolar-molar dişlerin interradiküler bölgesinde yerleşim gösteren düzensiz şekilli IO lezyonu

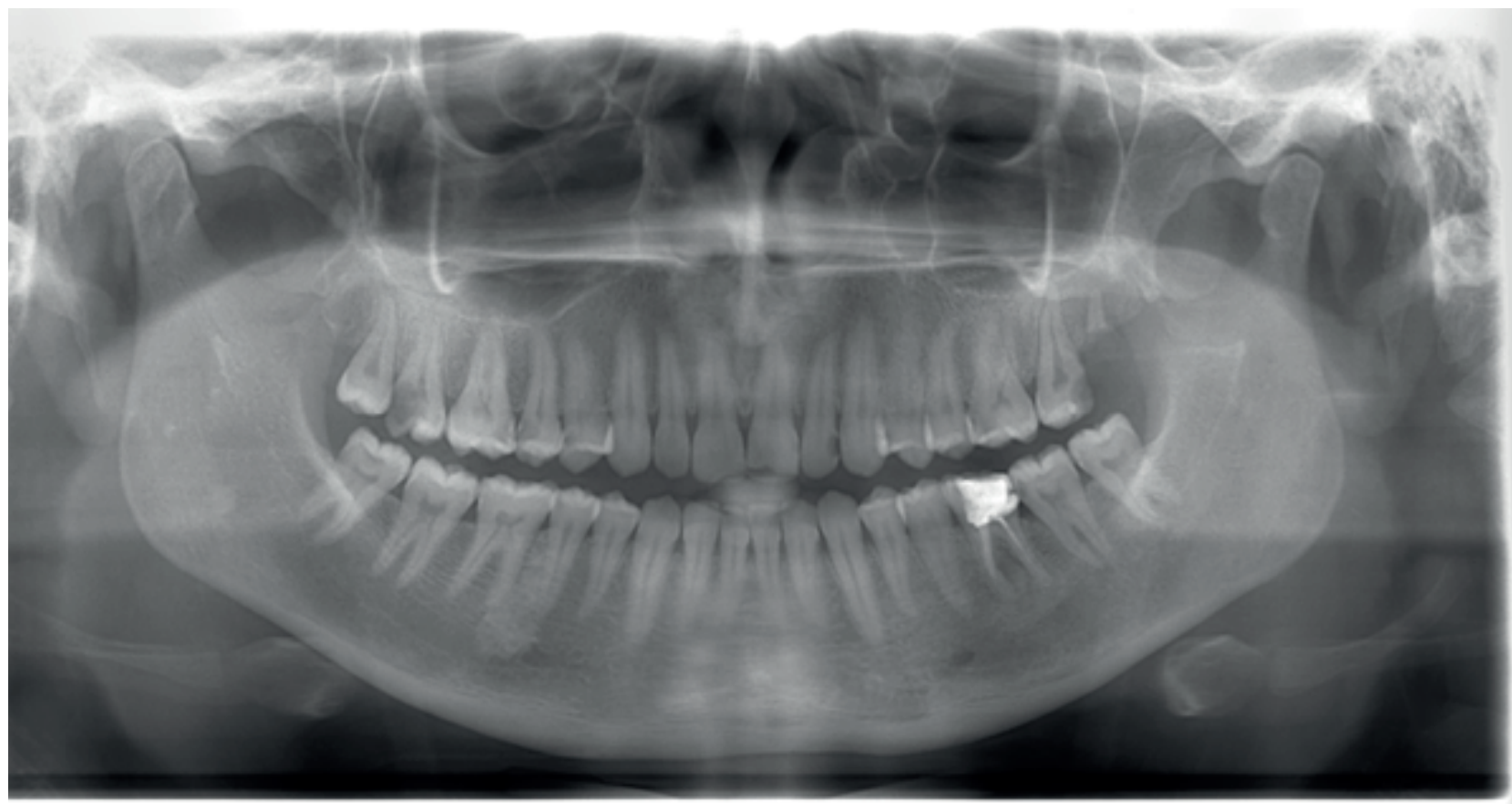

\section{Radyolojik inceleme}

Çevresinde radyolüsensi bulunmayan, normal kemikle ilişkili, sınırları düzenli, semptom göstermeyen, 3 mm'den büyük uniform radyoopasiteler IO tanımına uygun olarak ${ }^{9}$ çalışmaya dahil edilmiștir. Görüntüler iki gözlemci tarafından incelenmiş ve IO tanısı gözlemcilerin hemfikir oldukları görüntüler üzerinde konulmuştur. Herhangi bir uyuşmazlık olması halinde görüntü çalışmadan çıkartılmıştır.

\section{Dışlama kriterleri}

-Derin çürük, derin dolgulu, kanal tedavili dişler çevresindeki radyoopak lezyonlar (condensing osteitis) -Ekzostoz-torus, sialolit, tonsillolit, kalsifiye lenf nodunu düşündüren radyoopasiteler

-Gardner sendromuna ilișkin multiple radyoopak lezyonlar (osteoma, odontoma)

-Radyolüsent marjinle çevrili radyoopak lezyonlar -Fibro-osseoz hastalıkları düşündüren mikst radyoo- 
pak-radyolüsent lezyonlar

-Rezidüel diş köklerine ilişkin radyoopasiteler -İntraosseoz patolojilerin görüldüğü radyografiler -Düşük imaj kalitesine sahip radyografiler

-Metabolik kemik hastalığı olan bireyler çalışma dışında tutulmuştur.

\section{Görüntü eldesi}

İncelenen panoramik radyografiler üreticinin önerileri doğrultusunda oluşturulan rutin protokol kapsamında $70 \mathrm{kVp}, 5 \mathrm{~mA}$ ve $15 \mathrm{sn}$ işınlama parametrelerine göre 2D Veraviewpocs (J MORITA MFG corp, Kyoto, Japan) dijital panoramik röntgen cihazı ile elde edilmiștir.

\section{İstatistiksel analiz}

Verilerin analizinde SPSS v.21 (IBM Corp., Armonk, NY, USA) programı kullanılmıștır. Verilerin normal dağılıma uygunluğu Shapiro-Wilk testi ile değerlendirilmiştir. Tanımlayıcı istatistikler (ortalama, standart sapma) hesaplanmış ve kategorik verilerin analizinde (IO lezyonlarının varlı̆̆ ile yaş grupları ve cinsiyet arasındaki ilișki) ki-kare testi uygulanmıștır. Test sonuçlarının anlamlılıkları $\mathrm{p}<0.05$ seviyesine göre belirlenmiştir.

\section{BULGULAR}

1150 hastanın (613 kadın, 537 erkek) yaş ortalaması $38 \pm 15$ (kadınlarda $37 \pm 14$, erkeklerde $39 \pm 16$ ) yıldır. 1150 hastanın 103'ünde (\%9) toplam 122 IO lezyonu saptanmıştır. IO lezyonu varlığı ile yaş grupları ve cinsiyet arasında istatistiksel olarak anlamlı ilişki saptanmamıștır ( $p>0.05)$. IO görülen hastaların \%55.7'si kadın (68), \%44.3'ü (54) erkektir. I0 görülen hastaların yaş ortalaması $37 \pm 13$ olup lezyonların tamamı mandibulada görülmüştür. IO'nun yaş gruplarına göre dağılımı Tablo 1'de gösterilmiştir.

Tablo 1: IO lezyonlarının yaş gruplarına göre dağılımı

\begin{tabular}{|c|c|c|}
\hline Yaş grupları & IO lezyonu, $\mathbf{n}$ & $\%$ \\
\hline $10-20$ & 17 & 13.9 \\
\hline $21-30$ & 28 & 23 \\
\hline $31-40$ & 30 & 24.6 \\
\hline $41-50$ & 24 & 19.7 \\
\hline $51-60$ & 17 & 13.9 \\
\hline $61-70$ & 6 & 4.9 \\
\hline Toplam & 122 & 100 \\
\hline
\end{tabular}

IO en sık mandibula molar bölgede (\%45.9) daha sonra premolar bölgede (\%25.4) çoğunlukla düzensiz şekilli olarak (\%78.7) izlendi. Lezyonların \%45.1 (55) sağda, \%50'si (61) sol mandibulada, \%4.9'u (6) orta hat bölgesinde ve en sık dișten bağımsız mandibular alveolar kemikte (\%70.5) yerleşim göstermiştir. Diş apikalinde diş köküne bitișik olan 22 IO lezyonu bulunmaktadır. Bunların da 1 tanesi kanin kökünde, 11 tanesi premolar kökünde, 10 tanesi molar dişlerin kökünde yerleşim göstermiştir (Tablo 2 ve 3 ).

Tablo 2: IO lezyonlarının yerleşim bölgelerine göre dağılımları

\begin{tabular}{|c|c|c|}
\hline IO yerleşim bölgesi & IO lezyonu, $\mathbf{n}$ & $\%$ \\
\hline Molar & 56 & 45.9 \\
\hline Premolar & 31 & 25.4 \\
\hline Kesici & 7 & 5.7 \\
\hline Premolar-molar & 11 & 9 \\
\hline Kanin & 6 & 4.9 \\
\hline Kanin-premolar & 5 & 4.1 \\
\hline Kesici-kanin & 1 & 0.8 \\
\hline Ramus & 5 & 4.1 \\
\hline Total & 122 & 100 \\
\hline
\end{tabular}

Tablo 3: IO lezyonlarının dişlerle ilişkileri ve şekillerine göre dağılımı

\begin{tabular}{|c|c|c|}
\hline $\begin{array}{c}\text { IO'nun dişlerle } \\
\text { ilişkisi }\end{array}$ & I0 lezyonu, $\mathbf{n}$ & $\%$ \\
\hline Apikal & 22 & 18 \\
\hline İnterradiküler & 14 & 11.5 \\
\hline Dişten bağımsız & 86 & 70.5 \\
\hline Toplam & 122 & 100 \\
\hline IO şekli & & \\
\hline Oval-yuvarlak & 26 & 21.3 \\
\hline Düzensiz & 96 & 78.7 \\
\hline Toplam & 122 & 100 \\
\hline
\end{tabular}




\section{TARTIŞMA}

IO lezyonları non-ekspansif lokalize kemik radyodensiteleridir ve sağllk için risk teşkil etmezler ${ }^{7}$ ancak bu lezyonların ayırıcı tanısı condensing osteitis, semental displazi, ossifying fibroma, osteoma, osteoblastoma, sementoblastoma ${ }^{10}$ ve odontoma ile yapılmalıdır. Lezyonun radyolojik karakterinin bilinmesi ve dikkatli bir radyodiagnoz ile gereksiz biopsi prosedürünü önlemek mümkündür.7 Çalışmamızın amacı ilk muayene kliniğimize müracaat eden hastalarda IO sıklığını ve dağılımını panoramik radyografiler aracılığı ile belirlemektir. 1150 hasta ile yürüttüğümüz çalışmada 103 bireyde (\%9) en az bir bölgede IO lezyonu tespit edilmiştir. Kullanılan radyografik teknik, çalışmanın yürütüldüğü etnik grup ve IO’nun tanımlanmasına ilişkin farklı kriterler kullanılmasına dayanarak literatürde bildirilen IO sıklığı $\% 0.10$ ${ }^{7}$ - \% $31^{8}$ arasında değişkenlik göstermektedir. MacDonald-Jankowski ${ }^{11}$ IO'nun Çin ve Japon toplumlarında Batı ırkına göre daha yüksek prevalansa sahip olduğunu bildirmiştir. Türk toplumunda ise; Miloglu ve ark. ${ }^{12} 6.154$ bireyin panoramik radyografisi üzerinde yaptıkları çalışmada \% 2.44 , Kalyoncu ve ark. ${ }^{13}$ 500 dental volumetrik tomografi kaydı ile yürüttükleri çalışmada \%11.8, Demir ve Pekiner ${ }^{14} 279$ dental volumetrik tomografi kullandıkları çalışmada \%26.9, Toraman Alkurt ve ark. ${ }^{9} 1065$ panoramik radyografi yardımıyla gerçekleștirdikleri araştırmada \%4.7, Sisman ve ark. ${ }^{6} 2.211$ panoramik radyografiyle yapmış oldukları çalışmada \%6.1 prevalans değerine ulaşmıştır. Literatür incelendiğinde bu konudaki çalıșmaların genellikle panoramik radyografiler üzerinde yapıldığı görülmektedir. ${ }^{13}$ Yonetsu ve ark. ${ }^{15} \mathrm{IO}$ lezyonlarının tespiti için bilgisayarlı tomografi (BT) kullanan ilk araștırmacılar olmakla birlikte bu amaçla rutin BT kullanımı önermemişlerdir. IO tanısında ileri görüntülemeye ihtiyaç duyulması halinde dental volumetrik tomografi uygun radyolojik yöntemdir. ${ }^{16}$

Bazı araştırmacılar kadınlarda IO lezyonlarının daha sık görüldügüunü bildirmekle birlikte ${ }^{4}$ çalışmaların önemli bir kısmında cinsiyete göre IO dağılımının farklılık göstermediği bildirilmektedir. ${ }^{6,13-15,17} \mathrm{Bu}$ çalışmada elde edilen bulgular da bunu desteklemektedir. IO görülen hastaların \%55.7'si kadın, \%44.3'ü erkek olup cinsiyet ve IO arasında ilişki saptanmamiștır.

Çalışmamızda 16-92 yaş grubundaki bireylerin radyografileri incelenmiş olup IO sıklığı yaş gruplarına göre farklılık göstermemiştir. ${ }^{6,15,17}$ IO gözlenen en küçük yaş, çalışmamıza dahil edilen en küçük yaş olan 16 idi. Bununla birlikte literatürde IO lezyonlarının gözlenebildiği en küçük yaşın 9 olduğunu bildiren çalışmalar da bulunmaktadır. ${ }^{18,19}$ IO lezyonlarının yaşamın 3 ve 4. dekadlarında kümelendiği bildirilmiştir. ${ }^{6}$ $\mathrm{Bu}$ yaşlarda kemik formasyonunun pik yapmasının bu durumla açlklanabileceği öne sürülmektedir. ${ }^{14}$
İleri yaş gruplarında IO lezyonlarının daha büyük boyutlarda olduğu ölçümlenmiştir. ${ }^{13,18}$

İncelenen IO lezyonlarının tümü mandibulada ${ }^{20}$ ve en sık molar bölgede (\%45.9) ${ }^{14,16,21}$ tespit edilmiştir. Radyografik olarak $3 \mathrm{~mm}$ 'den büyük lezyonlar çalışmaya dahil edilmiș olup \%78.7'sinin şeklinin düzensiz olduğu tespit edilmiştir. Maksillar bölgedeki IO lezyonlarının tespit edilmesi anatomik yapıların superpozisyonu nedeni ile mandibular lezyonlardan daha güçtür. ${ }^{16}$

Eselman ${ }^{22}$ IO'nun reaktiften ziyade gelişimsel bir lezyon olduğunu ve kemiğin anatomik varyasyonu olduğunu bildirirken, MacDonald-Jankowski ${ }^{11}$ aşırı florürün etken olabileceğini öne sürmüștür. IO lezyonlarının kesin etiyolojisi belirsizliğini sürdürmekte olup kemiğe etki eden artmıș okluzal kuvvetlerin ilişkili olabileceği de düşünülmektedir. ${ }^{23}$ Hücresel seviyede bu lezyonların nedenini açığa çıkaran bir çalışma henüz bildirilmemiştir. ${ }^{20}$ Gelecekte okluzal kuvvetlerle bu lezyonların ilişkisinin açığa çıkarılmasını hedefleyen çalışmalara ihtiyaç duyulmaktadır. ${ }^{14}$

\section{SONUÇ}

IO lezyonu incelenen popülasyonda \%9 sıklığa sahiptir. Tedavi gerektirmeyen, periyodik kontrolü önerilen bu lezyonların yaş ve cinsiyetle ilişkisi bulunmamakta; en sık mandibula molar bölgede gözlenmektedir.

\section{KAYNAKLAR}

1. Marques Silva L, Guimaraes AL, Dilascio ML, Castro WH, Gomez RS. A rare complication of idiopathic osteosclerosis. Med Oral Patol Oral Cir Bucal 2007; 12: 233-4.

2. Greenspan A. Bone island (enostosis): current concept-A review. Skeletal Radiol 1995; 24: 111-5.

3. Moshfeghi M, Azimi F, Anvari M. Radiologic assessment and frequency of idiopathic osteosclerosis of jawbones: an interpopulation comparison. Acta Radiol 2014; 55: 1239-44.

4. McDonnell D. Dense bone island. A review of 107 patients. Oral Surg Oral Med Oral Pathol 1993; 76: 1248.

5. Halse A, Molven O. Idiopathic osteosclerosis of the jaws followed through a period of 20-27 years. Int Endod J 2002; 35: 747-51.

6. Sisman Y, Ertas ET, Ertas H, Sekerci AE. The frequency and distribution of idiopathic osteosclerosis of the jaw. Eur J Dent 2011; 5: 409-14.

7. Gamba TO, Maciel NAP, Rados PV, da Silveira HLD, Arús NA, Flores IL. The imaging role for diagnosis of idiopathic osteosclerosis: a retrospective approach based on records of 33,550 cases. Clin Oral Invest 
2020. (DOI: 10.1007/s00784-020-03477-0. Ahead of print).

8. Austin BW, Moule AJ. A comparative study of the prevalence of mandibular osteosclerosis in patients of Asiatic and Caucasian origin. Australian Dent J 1984; 29: 36-43.

9. Alkurt MT, Sadık E, Peker İ. Prevalence and distribution of idiopathic osteosclerosis on patients attending a dental school. J Istanbul Univ Fac Dent 2014; 48: 29-34.

10. Bsoul SA, Alborz S, Terezhalmy GT, Moore WS. Idiopathic osteosclerosis (enostosis, dense bone silands, focal periapical osteopetrosis). Quintessence Int 2004; 35: 590-1.

11. MacDonald-Jankowski DS. Idiopathic osteosclerosis in the jaws of Britons and of the Hong Kong Chinese: radiology and systematic review. Dentomaxillofac Radiol 1999; 28: 357-63.

12. Miloglu O, Yalcin E, Buyukkurt MC, Acemoglu H. The frequency and characteristics of idiopathic osteosclerosis and condensing osteitis lesions in a Turkish patient population. Med Oral Patol Oral Cir Bucal 2009; 14: 640-5.

13. Kalyoncu Z, Arslan A, Kurtuluş B, Sofiyev N, Onur ÖD. Çene kemiklerinde görülen idiyopatik osteosklerozisin Türk popülasyonundaki sıklığının belirlenmesi (Pilot Çalıșma). İstanbul Üniv Diș Hek Fak Derg 2012; 46: $1-10$.

14. Demir A, Pekiner FN. Idiopathic Osteosclerosis of the Jaws in Turkish Subpopulation: Cone-Beam Computed Tomography Findings. Clin Exp Health Sci 2019; 9: 117-23.

15. Yonetsu K, Yuasa K, Kanda S. Idiopathic osteosclerosis of the jaws: panoramic radiographic and computed tomographic findings. Oral Surg Oral Med Oral Pathol Oral Radiol Endod 1997; 83: 517-21.

16. Misirlioglu M, Nalçaci R, Adisen MZ, Yilmaz S. The evaluation of idiopathic osteosclerosis on panoramic radiographs with an investigation of lesion's relationship with mandibular canal by using cross-sectional cone-beam computed tomography images. J Oral Maxillofac Radiol 2013; 1: 48.

17. Kawai T, Hirakuma H, Murakami S, Fuchihata H. Radiographic investigation of idiopathic osteosclerosis of the jaws in Japanese dental outpatients. Oral Surg Oral Med Oral Pathol 1992; 74: 237-42.

18. Petrikowski CG, Peters E. Longitudinal radiographic assessment of dense bone islands of the jaws. Oral Surg Oral Med Oral Pathol Oral Radiol Endod 1997; 83: $627-34$

19. Lee SY, Park IW, Jang IS, Choi DS, Cha BK. A study on the prevalence of the idiopathic osteosclerosis in Korean malocclusion patients. Korean J Oral Maxillofac Radiol 2010; 40: 159-63.

20. Srivathsa S. Retrospective panoramic radiographic analysis for idiopathic osteosclerosis in Indians. J Indian Acad Oral Med Radiol 2016; 28: 242-5.

21. Ledesma-Montes C, Jiménez-Farfán MD, Hernández-Guerrero JC. Idiopathic osteosclerosis in the maxillomandibular area. Radiol Med 2019; 124: 27-33.

22. Eselman JC. A roentgenographic investigation of enostosis. Oral Surg Oral Med Oral Pathol 1961; 14: 1331-8.

23. Eversole LR, Stone CE, Strub D. Focal sclerosing osteomyelitis/focal periapical osteopetrosis: radiographic patterns. Oral Surg Oral Med Oral Pathol 1984; 58: 456-60. 